\title{
Modification of dispersion systems and its motion in cylindrical pipes
}

\author{
Kudrat Rakhimov ${ }^{1 *}$, Askar Babaev, ${ }^{2}$ Umar Chorshanbiev ${ }^{2}$, and Axror Obidjonov ${ }^{2}$ \\ ${ }^{1}$ Tashkent Institute of Irrigation and Agricultural Mechanization Engineers, Tashkent, Uzbekistan \\ ${ }^{2}$ Tashkent State Transport University, Tashkent, Uzbekistan
}

\begin{abstract}
This paper analyzes the dependence of properties of turbid flow on the dispersion composition and concentration of solid particles. The article presents the features of the transfer of river suspended solids and water in the pressure stations, that is, the effect on the distribution of kinematic and dynamic parameters of the flow of suspended particles of hydraulic transport.
\end{abstract}

\section{Introduction}

In construction, mining, chemistry, pressure pipelines are used for the hydrotransportation of dispersed systems. To increase their productivity, one of the most important tasks is creating calculation methods, in conjunction with the physicochemical and mechanical properties of the phases of the system, the composition of dispersed systems, their viscosity [1-3]. It is known that research works aimed at the development of energy-saving methods for ensuring the hydrotransport of dispersed systems through pressure pipes, as well as new methods and technologies for improving the methods of transferring dispersed systems through pipelines, taking into account their concentration, mechanical composition, and structure in such industries as the mining industry, water management, construction [4-7].

In the hydraulic transport of dispersed systems through pressure pipes, the main hydraulic parameters are pressure losses and the critical flow rate. Currently, the high energy intensity of hydrotransport systems used in production, particularly in the mining industry, construction, water management, is one of the main factors of the low efficiency of their functioning [8-10]. The essence of this process is determined by the peculiarities of dispersed systems, first of all, by the granulometric composition of solid particles and their volume concentration. The mutual influence of liquid and solid particles during their joint movement was revealed by a peculiar loss of pressure and determination of the carrying capacity of the flow [11-13]. The granulometric composition of solid particles of dispersed systems and their concentration affect both the change in the average flow rate and, as a result, the change in the hydraulic and energy parameters of the pressure system $[14,15]$.

\footnotetext{
* Corresponding author: qrakhimov.2019@mail.ru
} 
Modification of dispersed systems can be carried out at the stage of hydrotransportation. The use of low molecular weight organic materials and secondary products is promising. Modification of dispersed systems is a process in which a composition based on a liquid polymer binder penetrates into the pores and capillaries of particles of dispersed systems. For modification, solutions, dispersions, and melts of thermo- and thermosetting plastics, dispersions, and solutions of elastomers and some monomers, oligomers of secondary products of production are used. To improve the wettability of materials, surfactants are introduced into the impregnating composition $[16,17]$. The introduction of non-nanogenic surfactants in an amount of $0.5-3 \%$ facilitates the hydrotransport of dispersed systems. Surfactants promote effective dispersion of their particles, increase the speed and degree of hydrotransport, the service life of units and pipelines, and reduce hydrotransportation costs $[18,19]$.

In light of the foregoing, the purpose of this study is to modify dispersed systems to improve the method for calculating the kinematic and dynamic parameters of slurries in pressure pipes, taking into account the variability of the mechanical composition and the number of slurries.

\section{Methods}

The work uses standard methods and instruments, such as IR spectroscopy, viscometry, methods for studying hardness, adhesion, tribotechnical properties of dispersed systems, and also used experimental, field-observational, and generally accepted hydraulic methods, compiling mathematical models based on the laws of hydromechanics, together with topics, mathematical, statistical methods in the processing of experimental data.

\section{Results and discussion}

In construction, mining, chemistry, pressure pipelines are used for the hydraulic transport of dispersed systems. One of the methods is the modification of dispersed systems with low molecular weight organic compounds to increase their productivity. Gossypol resin, which is a secondary raw material of low-fat production, was selected as a modifier. The gossypol resin contains polyphenols, fatty acids, hydrocarbons, nitrogen- and phosphorus-containing compounds, as well as gossypol transformation products. Its appearance is a viscousflowing mass, color - from dark brown to black, the acid number of $\mathrm{KOH}-50-100 \mathrm{mg}$, ash content - 1.0-1.2 wt. \%, moisture, and volatile matter content - up to $4-6 \%$, solubility in acetone - 70-80 wt. \%, specific gravity 3-0.98-0.99 g / cm, saponification number $\mathrm{KOH}$ $80-130 \mathrm{mg}$.

In the work, we used gossypol resin of fat-and-oil plants, obtained from the distillation of fatty acids at a temperature of $220-2300 \mathrm{C}$, containing in its composition from 40 to $50 \%$ of condensation, polymerization, and reaction products of gossypol. Modified dispersed systems are formed in the hearth of a metallurgical plant with $1 \%$ gosypolovy resin.

When obtaining the equations of motion of modified dispersed systems (MDS) in pipelines, stable motion in cylindrical pipelines was considered as a two-phase flow based on mathematical models $[4,6,11]$. Using one of the basic equations of hydrodynamics - the theorem on the quantitative change in motion, separate equations for the flow of liquid and 
modified solid particles of a two-phase (liquid + modified solid particles) flow, stably moving through a cylindrical pipe, have been compiled.

As a result, the change in pressure along the length of the pressure pipeline $\mathrm{L}$ according to the laws of hydraulics and concerning the speed of each phase is expressed as follows:

$$
\Delta P=\rho_{1}\left(1-C_{0}\right) \frac{\vartheta_{1}^{2}}{2}+\rho_{2} C_{0} \frac{\vartheta_{2}^{2}}{2}+K_{1}\left(\rho_{1}\left(1-C_{0}\right) \vartheta_{1}^{2}+\rho_{2} C_{0} \vartheta_{2}^{2}\right)+K\left(\vartheta_{1}-\vartheta_{2}\right)^{2}
$$

where: $K_{1}=\frac{\lambda L}{2 D}$ is coefficient of phase interaction;

$\rho_{1}$ is the density of the liquid; $C_{0}$ is concentration of solid particles; $\rho_{2}$ is the density of solid particles; $\lambda$ is coefficient of hydraulic friction.

$\vartheta_{1}$ is the flow rate of the fluid; $\vartheta_{2}$ is the speed of solid particles; $\Delta L$ is the distance between the considered sections; $\Delta P$ is the pressure difference between sections; $\mathrm{D}$ is the pipeline's diameter.

The peculiarity of this expression is that the difference between the change in the pressure of the fluid flow and the flow rate of the modified solid particles leads to a change in the value of the hydraulic resistance. This suggests that the greater the difference in speed, the higher the head loss can be. The movement of modified solid particles occurs simultaneously with the carrier liquid itself and at a minimum speed of interfacial slip. Using the above expressions, the liquid flow rate $Q_{1}$ and the solids flow rate $Q_{2}$ are respectively determined in the order shown:

$$
Q_{1}=\omega_{1} \cdot \vartheta_{1} ; \quad Q_{2}=\omega_{2} \cdot \vartheta_{2}
$$

where $\omega_{1}, \omega_{2}$ are, respectively, the area of the flow of liquid and solid particles;

$\omega_{1}=\omega\left(1-C_{0}\right)$ is fluid flow area; $\omega_{2}=\omega C_{0}$ is the area of flow of solid particles, $C_{0}$ is the concentration of solid particles.

$$
\vartheta=\vartheta_{2} C_{0}+\vartheta_{1}\left(1-C_{0}\right) \quad \vartheta=\vartheta_{1}+\vartheta_{12} C_{0}
$$

where $\vartheta_{12}$ is the sliding speed;

The specificity of MDS movement in cylindrical pipes was considered a critical mode of movement and during the movement of modified solid particles through pipes as a minimum hydraulic resistance. Changes in hydraulic resistance in dispersed systems were considered a relationship between the forces of friction and pressure. The dependence of the critical velocity of dispersed systems corresponding to the critical regime, depending on many factors, including the volume concentration of solid particles, particle size distribution, as well as physical and mechanical characteristics, the pipe diameter is reflected to a certain extent in many works of scientists $[20,21]$. 
In the studies carried out, the study of the dependence of the critical velocity on the average particle diameter showed that the structure of the modified solid particle and the value of its velocity affect a certain limiting value of the particle size itself. When evaluating the value of the critical speed, it is necessary to consider the granulometric composition of the modified solid particles separately. Based on the above facts, the following formulas are proposed for calculating the critical velocity, proceeding from the equilibrium state of friction and pressure forces for the flow under consideration, the critical velocity for a slurry with solid particles of the same diameter:

$$
\vartheta_{\kappa p}=\sqrt[3]{\frac{\alpha D}{\mu_{2} \lambda_{2}}} \sqrt[3]{d_{i}^{2}}
$$

The following formula for the critical velocity for dispersed systems with modified solid particles of various diameters is proposed:

$$
\vartheta_{\kappa p}=\beta \cdot \sqrt[3]{\frac{\alpha D}{\mu_{2} \lambda_{2}}} \sqrt[3]{d_{i}^{2}}
$$

where $\lambda_{2}$ is the coefficient of hydraulic friction of dispersed systems; $d_{i}$ is solid particle diameter, $\mathrm{D}$ is pipeline diameter; $\mu_{2}-$ is the dynamic coefficient of dispersed systems, $\alpha$ is coefficient.

The coefficient taking into account the heterogeneity of the composition of modified solid particles:

$$
\beta=f\left(\frac{d_{10}}{d_{90}}\right)
$$

where: $d_{10}$ and $d_{90}$ are respectively, the amount of modified solid particles in percent, $d_{10}$ and $d_{90}$ is determined based on the granulometric composition of the modified solid particle. Using certain possibilities of the theory of motion of modified dispersed systems in pressure pipelines, the calculated dependences of the hydraulic parameters of the hydrotransport of modified solid particles through the proposed critical speed are proposed.

The research was carried out in such production facilities as pressure pipelines of a mining and metallurgical plant. In the studies carried out, surveys were carried out in pressure pipes with various concentrations of dispersed systems. Hydraulic processes in pressure pipelines were studied as highly concentrated dispersed systems. The concentration value in the flow was $\mathrm{C}_{0}=0.4-0.6$. In the studies carried out, along with the hydraulic processes of the flow, the granulometric composition of solid particles in the structure of dispersed systems was also studied (Figure 1). 


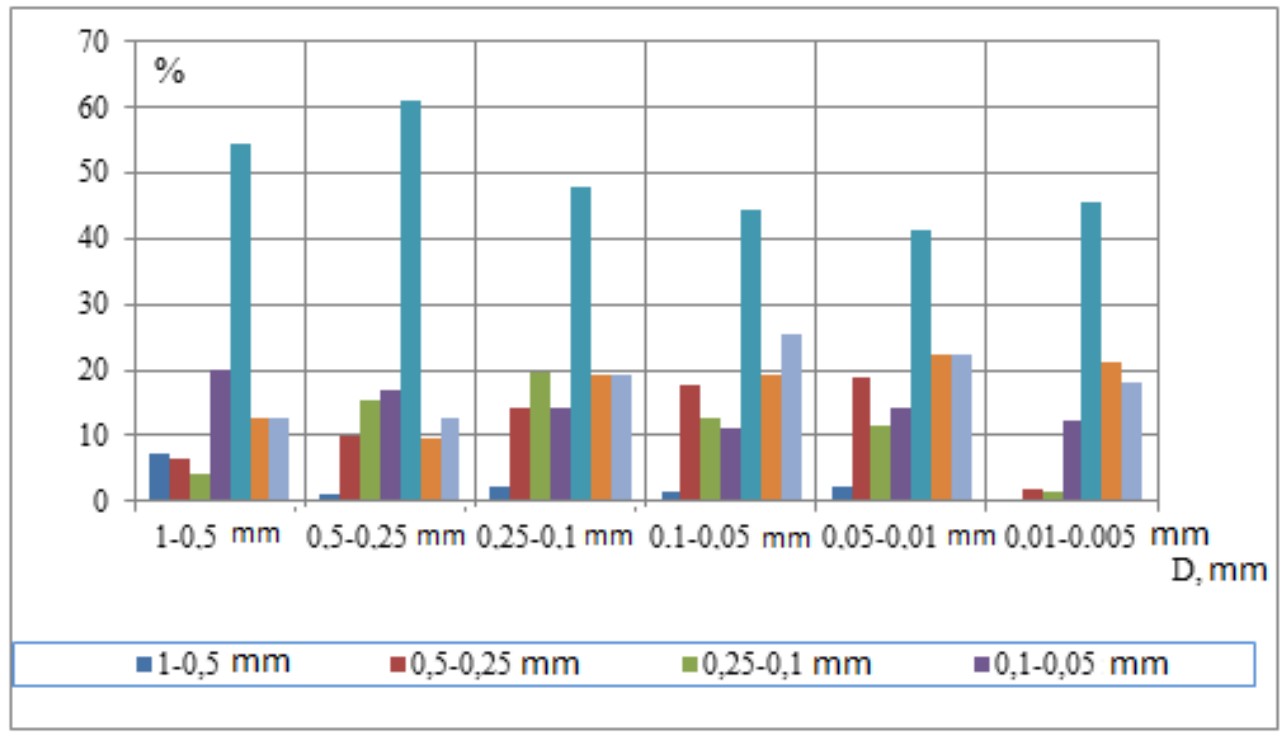

Fig. 1. Histogram of the fractional composition of dispersed systems

The influence of the granulometric composition of solid particles on the carrying capacity of dispersed velocity systems has been studied (Fig. 2).

Based on the results obtained, the critical state of the flow was estimated. An analytical dependence is given for the coefficient taking into account the different sizes of a solid particle, $\beta$ which is the main parameter in determining the critical velocity. Taking advantage of the known possibilities of the theory of the movement of solid particles of flow through pressure pipes, the calculated dependences of the hydraulic parameters of the hydrotransport of modified dispersed systems in the proposed pipe systems are proposed.

The hydraulic calculation of its parameters during hydrotransport is carried out as follows: the particle size distribution of solid particles, the length of the pipe $\mathrm{L}$, the density of the solid particle, the density of water, the concentration of the solid particle $\mathrm{C}$, the flow rate of the solid particle Q, the carrying capacity of the flow are determined. It is necessary to determine the flow rate of water capable of carrying out the flow rate of a given solid particle during hydrotransportation, as well as to determine the critical velocity of dispersed systems in the pipe, which can provide the volumetric flow rate in the critical mode of hydrotransportation [22-24]. 


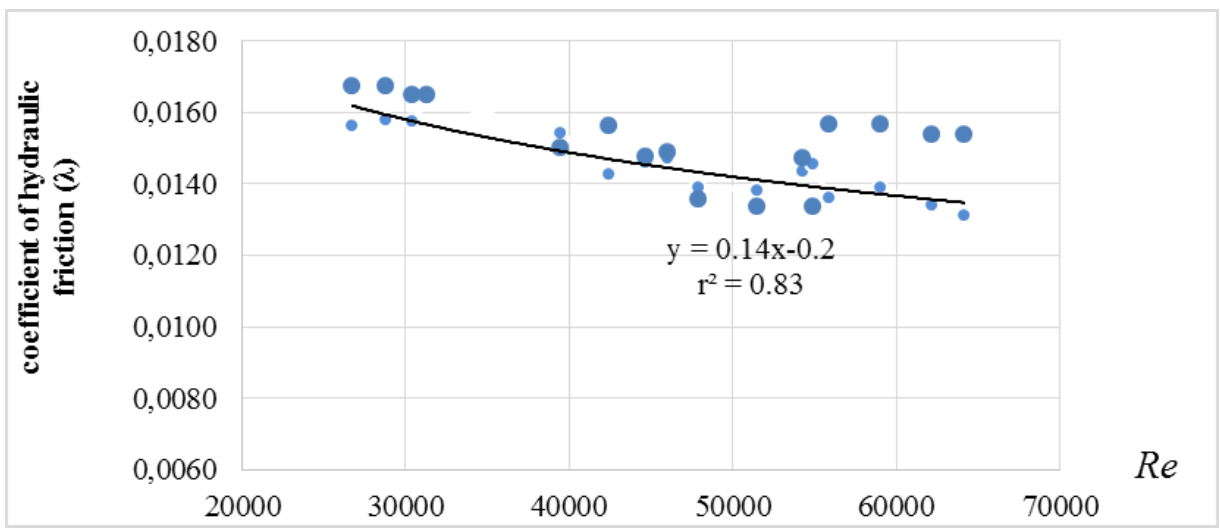

Fig. 2. Graph of the dependence of the coefficient of hydraulic friction on the Reynolds number

Having determined the specific head loss in the pressure pipes, we will also reveal the given flow rate for modified dispersed systems and the required pressure for hydraulic transport:

$$
I=\frac{\lambda_{2}}{D} \cdot \frac{Q^{2}}{\omega^{2} \cdot 2 g} .
$$

Based on these equations, it is possible to trace changes in the pressure loss due to changes in the speed of modified dispersed systems (Fig. 3).

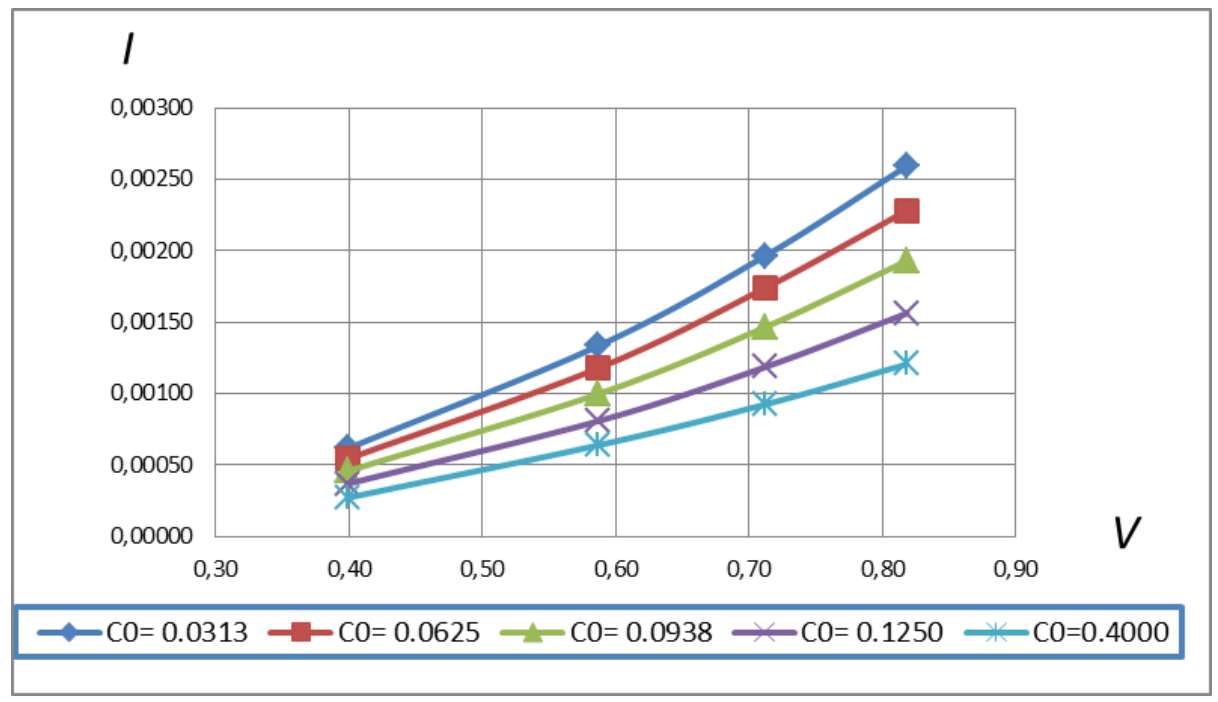

Fig. 3. Graph of specific hydraulic resistances in dispersed systems

As can be seen from this graph, as a result of an increase in the value of the slurry concentration, changes are also observed between the specific hydraulic resistance of the flow and the flow rate.

The flow rate of slurry in the pressure pipes, based on the above results, can be determined as follows: 


$$
Q_{2}=\omega \cdot \vartheta_{\kappa p}
$$

Thus, new dependencies are recommended for the critical speed and flow rate of modified dispersed systems, leading to a minimum value of hydraulic resistance in pressure pipes.

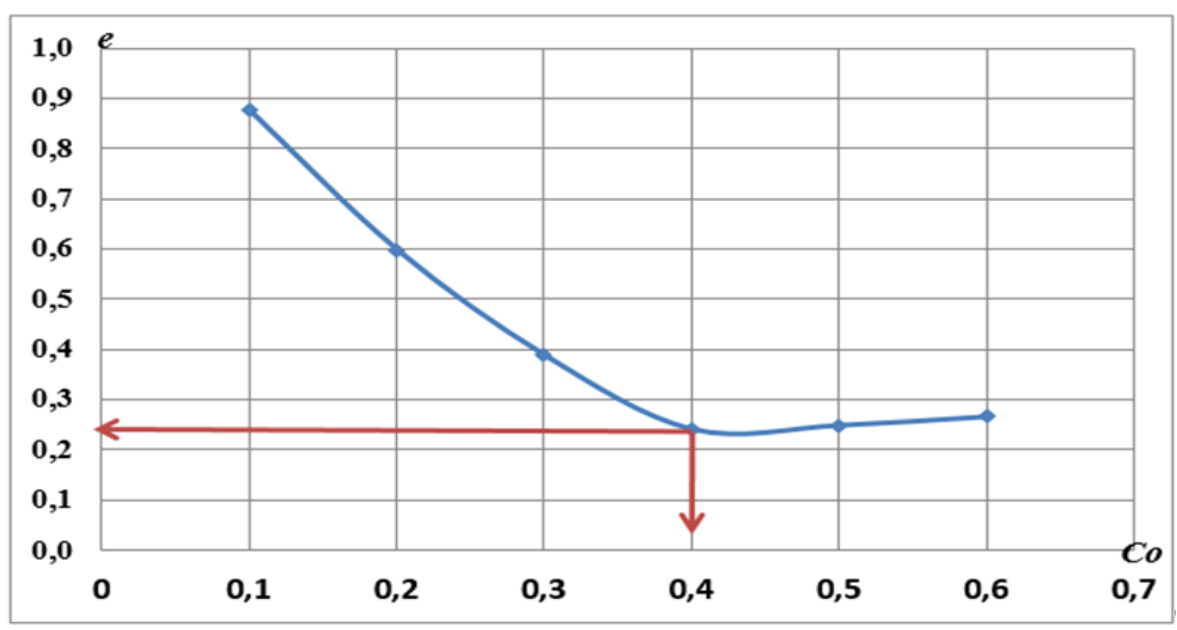

Fig. 4. Graph of the change in the comparative energy together with the change in the concentration of modified dispersed systems in hydrotransport

When assessing the operating mode of the hydrotransport system in pressure pipes, along with an increase in the concentration of modified dispersed systems, a decrease in its hydraulic resistance and the amount of electricity is observed compared with unmodified disperse systems. Therefore, in this study, by finding the critical velocity that takes into account solid particles consisting of various fractions, they were determined using the graph (Fig. 4), which provides the minimum values for hydraulic resistance and energy for unmodified dispersed systems [25-27].

The flow parameters in the process of hydrotransportation are calculated as follows: Where:

Slurry head:

$$
H_{\Gamma}=H\left(1+\frac{C_{0}^{1,2}}{0,45}\right)
$$

Specific weight of slurry:

$$
\gamma_{\Gamma}=\gamma_{B}\left(1+\left(\frac{\gamma_{T}}{\gamma_{B}}-1\right) C_{0}\right)
$$

Slurry power: 


$$
N_{\Gamma}=\gamma_{\Gamma} H_{\Gamma} Q_{\Gamma}
$$

Specific energy:

$$
E=\frac{N_{\Gamma}}{Q_{T}}
$$

During the calculated period, the power consumption of hydrotransport, provided with the parameters and concentration of modified dispersed systems, will decrease by an average of $17 \%$. In addition, in the studies carried out in the mining industry, the hydraulically most advantageous pipe diameter was determined. As a result, metal consumption is reduced by $19 \%$.

\section{Conclusion}

As a result, the recommended modifying additives gosypol resin for dispersed systems and its movement in cylindrical pipes; an operating model that takes into account the concentration of turbidity in the flow and the structural composition of dispersed systems; methods for calculating the flow parameters in the process of hydrotransport of modified dispersed systems for the hydraulically most favorable state, taking into account the variability of its concentration, recommended in cylindrical pipes of specific head losses for liquid and solid flow and the effect of variability of the mechanical composition of particles and concentration of turbidity on the flow rate and power of the modified dispersed system, substantiated the dependence of the hydraulic friction coefficient on the flow regime, taking into account the variability of the concentration of solid flow in modified dispersed systems, based on the statistical analysis of the data obtained, the correlation coefficient was $(\mathrm{r} 2=0.83)$, a mathematical expression of the relationship between the coefficients flow rate and Reynolds number, a method of calculating, based on theoretical and experimental studies, the carrying capacity of the flow corresponding to the minimum specific energy in cylindrical pipes in the process of pressure hydrotransport is recommended.

\section{Reference}

1. Zheleznyakov G.V., Talmaza V.F. Dependence of the parameters of velocity profiles on hydraulic resistance. Hydrotechnical construction.- №8. - pp.33-35, (1973)

2. lkhomov Kh.Sh,. Study of the interaction coefficient for a two-phase flow in a horizontal pipe. Uzbek journal of problems of mechanics. pp.48-51, (1995)

3. Karasik V.M., Asaulenko I.A. Pressure hydrotransport of sandy materials. - Kiev: Nauk. dumka, - p.107, (1965)

4. A. V. Karaushev Theory and methods for calculating river sediments. - L: Gidrometeoizdat, - p.272, (1977)

5. Arifjanov A.M., Latipov N.K., Babaev A.R. To the formation of the concentration field of the suspended flow in pipelines // Bulletin of the Tashkent Institute of Railway Engineers.- №1, - pp.49-54, (2018)

6. Arifjanov, A., Gapparov, F., Apakxujaeva, T., Xoshimov, S. Determination of reduction of useful volume in water reservoirs due to sedimentation (2020) IOP 
Conference Series: Earth and Environmental Science, 614 (1).DOI: 10.1088/17551315/614/1/012079.

7. Arifjanov, A., Jonqobilov, U., Jonqobilov, S., Khushiev, S., Xusanova, J. The influence of hydraulic friction on the maximium pressure of water hammer (2020) IOP Conference Series: Earth and Environmental Science, 614 (1). DOI: 10.1088/1755-1315/614/1/012092.

8. Arifjanov, A., Samiev, L., Apakhodjaeva, T., Qurbonov, X., Yusupov, Sh., Atakulov, D. Processes of Mirishkor channel using GIS technologies (2020) IOP Conference Series: Materials Science and Engineering, 918 (1). DOI: 10.1088/1757899X/918/1/012143.

9. Kenjabaev, S., Arifjanov, A., Frede, H., Apakhodjaeva, T. Ecohydrology of the Syrdarya River under irrigation water management in the Fergana Valley (2020) IOP Conference Series: Materials Science and Engineering, 883 (1). DOI: 10.1088/1757899X/883/1/012081.

10. Arifjanov, A., Xodjiyev, N., Jurayev, S., Kurbanov, K., Samiev, L. Increasing heat efficiency by changing the section area of the heat transfer pipelines (2020) IOP Conference Series: Materials Science and Engineering, 869 (4). DOI: 10.1088/1757899X/869/4/042019.

11. Arifjanov, A., Rakhimov, K., Abduraimova, D., Babaev, A., Melikuziyev, S. Hydrotransport of river sediments in hydroelelators. (2020) IOP Conference Series: Materials Science and Engineering, 869 (7). DOI: 10.1088/1757-899X/869/7/072003.

12. Arifjanov, A., Fatxullaev, A. Natural Studies for Forming Stable Channel Sections (2020) Journal of Physics: Conference Series, 1425 (1). DOI: 10.1088/17426596/1425/1/012025.

13. Arifjanov, A., Rakhimov, Q., Samiev, L., Abduraimova, D., Apakhodjaeva, T. Hydraulic friction coefficient at hydraulic mixing movement in pressure pipelines (2020) Journal of Advanced Research in Dynamical and Control Systems, 12 (7 Special Issue), pp. 1332-1336. DOI: 10.5373/JARDCS/V12SP7/20202233.

14. Arifjanov, A., Juraev, S., Samiev, L., Ibragimova, Z., Babajanov, F. Determination of filtration strength and initial filtration gradient in soil constructions. (2020) Journal of Advanced Research in Dynamical and Control Systems, 12 (4 Special Issue), pp. 1860-1864. DOI: 10.5373/JARDCS/V12SP4/20201672.

15. Arifjanov, A., Rakhimov, K., Abduraimova, D., Akmalov, S. Transportation of river sediments in cylindrical pipeline (2019) IOP Conference Series: Earth and Environmental Science, 403 (1). DOI: 10.1088/1755-1315/403/1/012154.

16. Arifjanov, A., Samiev, L., Apakhodjaeva, T., Akmalov, S. Distribution of river sediment in channels. (2019) IOP Conference Series: Earth and Environmental Science, 403 (1). DOI: 10.1088/1755-1315/403/1/012153.

17. Arifjanov, A., Akmalov, S., Akhmedov, I., Atakulov, D. Evaluation of deformation procedure in waterbed of rivers. (2019) IOP Conference Series: Earth and Environmental Science, 403 (1). DOI: 10.1088/1755-1315/403/1/012155.

18. Arifjanov, A., Apakhodjaeva, T., Akmalov, S. Calculation of losses for transpiration in water reservoirs with using new computer technologies. (2019) International Conference on Information Science and Communications Technologies: Applications, Trends and Opportunities, ICISCT 2019. DOI: 10.1109/ICISCT47635.2019.9011883.

19. Arifzhanov, A.M. Method for calculation of the distribution of drift particles in variable section beds (VSB) Gidrotekhnicheskoe Stroitel'stvo, (2), pp.44-45, (2004)

20. Arifzhanov, A.M. Distribution of Suspended Sediment Particles in a Steady-State Flow. (2001) Water Resources, 28 (2), pp. 164-166. DOI: 10.1023/A:1010375500148. 
21. Arifjanov, A., Otaxonov, M., Samiev, L., Akmalov, S. Hydraulic calculation of horizontal open drainages (2019) E3S Web of Conferences, 97. DOI: 10.1051/e3sconf/20199705039.

22. Rakhimov, K., Ahmedkhodjaeva, Xoshimov, S. Theoretical bases of hydraulic mixture in round cylindrical pipelines (2020) IOP Conference Series: Earth and Environmental Science, 614 (1). DOI: 10.1088/1755-1315/614/1/012095.

23. Samiyev, L., Allayorov, D., Atakulov, D., Babajanov, F. The influence of sedimentation reservoir on hydraulic parameters of irrigation channels (2020) IOP Conference Series: Materials Science and Engineering, 883 (1). DOI: 10.1088/1757899X/883/1/012031.

24. Fatxulloyev, A., Abduraimova, D., Otakhonov, M., Atakulov, D., Samiev, L. Method designing of open drainages (2020) IOP Conference Series: Materials Science and Engineering, 883 (1). DOI: 10.1088/1757-899X/883/1/012047.

25. Fatxulloyev, A., Abduraimova, D., Otakhonov, M., Atakulov, D., Samiev, L. Method designing of open drainages (2020) IOP Conference Series: Materials Science and Engineering, 883 (1),.DOI: 10.1088/1757-899X/883/1/012047.

26. Muratov, A., Melikuziev, S. Technology of formation of combined products of meliorative purpose (2020) IOP Conference Series: Materials Science and Engineering, 883 (1). DOI: 10.1088/1757-899X/883/1/012060.

27. Lee, A., Usmonov, T., Norov, B., Melikuziev, S.Advanced device for cleaning drain wells (2020) IOP Conference Series: Materials Science and Engineering, 883 (1).DOI: $10.1088 / 1757-899 X / 883 / 1 / 012181$. 